\title{
Stuttering risk: neurophysiological and genetic findings versus psychosocial insights. a proposalfor a resolution
}

\begin{abstract}
In the search for the causes of developmental stuttering the findings have constantly proved contradictory. Despite the huge body of knowledge about stuttering its cause is still considered to be unknown; the psychological background is recognized as important, but stuttering is currently regarded as a pure neurological problem. It is generally agreed that therapy should be multidimensional but in fact there is a widespread opinion that the dysfunction has genetic roots. This surprising lack of agreement is blocking the advance of research and the development of therapeutic approaches. In addition, there are serious shortcomings in the currently favored methodology of stuttering research: evidence-based medicine and practice have reduced the amount of high-grade evidence research data to such an extent that much useful information has been lost; the relevance of functional magnetic resonance imaging is controversial, and the hope that one day genetic engineering will correct stuttering-related mutations without severe side effects is unrealistic. A change of approach to research and therapy is required. If this cannot be found on the basis of a generally accepted notion of the cause of stuttering, it must emerge from the search for the best existing therapeutic approach.

Conclusion:The present paper offers an evaluation of the basic finding of modern outcome research that the factor of a specific therapeutic approach has less impact on outcome than the common factors, especially the clinician-client relationship. In Speech Language Pathology, and notably in stuttering research and clinical practice, it would be wise to implement this understanding in the form of chempathy-based therapies. The requirements for developing the skills for this approach are discussed.
\end{abstract}

Keywords: stuttering, criticism of ebp, empathy based therapy, common factors, clinician-client relationship
Volume I Issue 7 - 2014

\author{
Jurg Kollbrunner, Sandra Fritschi Wedell, \\ Alexander Zimmermann, Eberhard Seifert \\ Department of Otorhinolaryngology, Switzerland
}

Correspondence: Jurg Kollbrunner, Division of Phoniatrics, Department of Otorhinolaryngology, Head Neck Surgery, University of Berne, Inselspital, CH-30I0 Bern, Switzerland, Tel 417939596 69, Email juerg.kollbrunner@insel.ch

Received: October 31, 2014 | Published: November 28, 2014
Abbreviations: SLPs, speech language pathologists; RCTs, random controlled trials; EBP, evidence based practice

\section{Introduction}

Three scientific debates in the last few years create the alarming impression that some basic developments in the exploration of the causes of stuttering and the outcome of therapies has led into a blocking situation for further research and practice. These are the debate triggered by an article concerning behavior therapy with stuttering school-age children ${ }^{1}$ to which over one hundred SLPs reacted strongly Yaruss et al., ${ }^{2}$ a controversy between Mc Curtin and Roddam $^{3}$ and Erickson and Perry ${ }^{4}$ about whether Speech Language Pathologists (SLPs) find themselves "under siege" by Evidence Based Practice (EBP); and finally the reactions of professionals to the film "The King's Speech".

Marilyn Nippold ${ }^{1}$ complained in an editorial about a trend in the literature toward counseling children to accept their stuttering and to learn to cope with its negative side effects instead of working directly on the stuttering itself. For her, this amounts to "throwing in the towel on the effort to achieve fluency", and she praised the behavioristic "Lidcombe Program" and even more the "Gradual Increase in Length and Complexity of Utterance", a "programmed" approach with a "drill-like nature" which is "fairly easy to administer". Yaruss et al., ${ }^{2}$ replied on behalf of 110 SLPs and people who stutter, criticizing Nippold's "seemingly narrow focus on treatment aimed at 'building fluent speech"". They strongly advocated a more comprehensive approach which addresses not only increased fluency but also greater acceptance of stuttering, thus reducing secondary behaviors, minimizing avoidance, improving communication skills, increasing self-confidence and managing bullying effectively. Nippold ${ }^{5}$ reacted to this criticism with the statement that secondary behaviors and situational avoidances seem to arise because children are unable to manage their primary disorder; stuttering would diminish if the child could control it. She explained her narrow focus on treatment by alluding to the large caseloads of SLPs, the fact that most SLPs do not receive extensive training as counselors and the remark that school-based SLPs are not expected to manage by themselves all the problems that impact their clients. Here it is to say that if a broader focus on treatment is considered to be crucial but the caseload is too large, one has to fight for more staff and not pretend that everything is okay. And the fact that SLPs are not fully trained counselors does not relieve them of adopting a comprehensive approach to their clients. On the other hand, Nippold's reaction raises questions which have still not been answered satisfactorily: To what extent should SLPs think and act psychologically and how can they learn to do this?

Mc Curtin and Roddam $\mathrm{H}^{3}$ describe the use of EBP within the speech pathology profession, which uses Random Controlled Trials (RCTs) as its 'gold standard' in experimental research, as leading to a reduction in the amount of data produced, which in turn may lead to a loss of significant information. The narrow focus of methodologies which can declare themselves to be "evidence-based" results in a professional knowledge base which may be incomplete, incorrect, with a "minimum of useful information for the clinician". ${ }^{6}$ Treatment that cannot be subjected to RCTs may be discouraged-and in the 
field of SLP a lot of research is carried out which does not result in numerically countable results. That is why the two authors describe the modern coactive demand of EBP as a burden which puts SLPs "under siege" and why they advocate another definition of "evidence", namely one that favors specific clinical training. Erickson and Perry ${ }^{4}$ admit that many of the requirements made of speech pathologists may be considered burdensome, but in the case of EBP it is a "burden" that ensures patients receive the best quality care. RCTs, the core of EBP, were developed initially in the field of medicine for use in drug trials. Is it not important to investigate whether evidence in a field like SLP can be tested using the same methods as in physiology? Erickson and Perry also criticize Mc Curtin's and Roddam's question as to whether EBP accommodates the realities of the workplace, and describe as self-evident the demand that the workplace should accommodate EBP. But this is only logical if it is the case that EBP is the best instrument to survey SLP practice.

"The King's Speech", a movie portrayal of King George VI, has made stuttering therapy "a hot topic worldwide", ${ }^{7}$ not only thanks to its excellent actors and the absorbing story set shortly before the beginning of the Second World War, but also because it presents the Australian speech therapist Lionel Logue using the methods of speech therapy of that time, treating the stuttering Prince Albert in a way which revives the old question of whether stuttering is a solely physical impairment or the consequence of psychological trauma. And more than this: the film gives the impression that Prince Albert's stutter was the direct result of traumatic incidents in his childhood. ${ }^{8,9}$ In Logue's therapy the prince found a way "to confront the shadow of his abusive childhood", ${ }^{10}$ so that his symptoms were no longer needed for homeostatic balance. ${ }^{11}$ In contemporary research about the causes of stuttering, there is little room for psychodynamic theories. Why did this film appear so believable? Because the film's screenwriter, David Sidler, used to stutter himself? Or because good therapists have always known that stuttering can only be understood and successfully treated by taking into account the life experiences of the persons concerned and their dreams for the future?

\section{Meandering in the search for the causes of stuttering}

Up until the $19^{\text {th }}$ century stuttering was thought to be caused by a physical deformation, an explanation which led to treatment through exercising the muscles of mastication (speaking with pebbles in the mouth) or surgical interventions (resection of part of the tongue). At the turn of the century SLPs in Austria and Germany thought of the disorder as a functional problem and developed a variety of exercises to correct the dysfunction. It was around the same time that psychoanalytical theories and techniques were first used, especially in the USA. The beginnings of modern stuttering research took place at the University of Iowa, wherein 1927 Lee Edward Travis, the first SLP to obtain a Ph.D., became director of a Speech and Hearing Clinic. With his assistants, Wendell Johnson and Charles van Riper, he began to treat PWS on the basis of the assumption that stuttering is an effect of disturbed hemispheric dominance. But Johnson gradually developed the theory that "diagnosis" by well-meaning parents and attempts to correct the "stuttering" of a child when it is just learning to talk in fact contribute to the development of the problem. "Stuttering often begins not in the child's mouth, but in the parent's ear", he said. However, with the emergence of psychological behavioral therapy, Johnson's "diagnosogenic theory" became less attractive, and even today critics worldwide claim that Johnson did no more than blame "many millions of parents". ${ }^{2}$ In the following decades plenty of etiological hypotheses were put forward. Most of them fall into one of the following categories: "break-down hypotheses" (stuttering as a functional failure in the brain), "anticipatory-struggle hypotheses" (stuttering as a reaction towards the anticipation of speech problems) and "unconscious-need hypotheses" (stuttering as an attempt to fulfill two opposite needs at the same time).A large area of etiological theories focuses on linguistic issues: Stuttering as an abnormal interaction between semantic processing and phonological encoding, as disturbed synchronicity between paralinguistic and linguistic systems or as a covert repair of elements wrongly placed in the memory for articulation. Such mechanisms were supposed to be closely connected to defective neurophysiological processes and those again were thought to be the result of a hereditary defect, an aberration of one or more genes. In addition to these physiological approaches to the nature of stuttering, extensive research has been undertaken into psychosomatic etiological factors. Between1939 and 1991 at least 59 studies looked for intergroup differences of psychosocial factors between stuttering and non-stuttering adults, children and their families. 48 of these studies showed positive correlations between stuttering and psychosocial factors, 7 studies showed no such correlation and only 4 studies resulted in negative correlations. ${ }^{13}$ These results supported psychosomatic theories concerning the etiology of stuttering. ${ }^{14}$ explained that the roots of stuttering lie in disturbed interpersonal relationships, ${ }^{15}$ declared that stuttering is not a speech disorder but a disorder of the social representation of the self, a self-role conflict, and Krause ${ }^{16}$ called stuttering a "relation disorder".

Specialist neo-psychoanalysts such as Peter Glauber, Dominick Barbara, Albert Murphy, Gertrud L. Wyatt and Lee Edward Travis developed detailed concepts for applying the psychodynamics and family dynamics of stuttering to research and in therapies. Psychosomatic-oriented therapists have used striking expressions to warn their somatic-oriented colleagues against their basically symptom-related view: Sheehan ${ }^{15}$ wrote: "Defining stuttering as a fluency problem borders on professional irresponsibility. It ignores the person". ${ }^{17}$ described a therapy restricted to fluency as sadistic, ignorant and frequently both, and ${ }^{18}$ explained that the stuttering child can only find peace once the family system enables him to do so. As the methods of behavior therapy and its enhanced version, cognitive behavior therapy, were extended, these warnings were more and more ignored. Representatives of mainstream stuttering research have settled for the position that stuttering is a "multi-causal", "multidimensional" or "multi factorial" disorder;" ${ }^{19}$ descriptions which apply to any disorder but allow thinking that the attention for the psychosocial background is a matter of course. Current attempts to find the cause of stuttering are dominated by two different research strategies. One is the search for neurophysiological causes, using functional magnetic resonance imaging (fMRI) while the other focuses on genetics, using pedigree-studies and molecular-genetic analysis. Both fields of research have delivered sensational results but ones that are also extremely problematic.

\section{The problems of functional Magnetic Resonance Imaging (fMRI) studies}

In fMRI-studies the blood flow (and hence the distribution of oxygen) is measured in different areas of the brain during specific cognitive or motor activities. Comparative studies with people who stutter (PWS) and people who do not stutter (PWNS) have demonstrated differences in brain function and even in brain anatomy, involving both auditory and motor areas of the brain. These differences result in abnormal laterality of auditory-motor interaction for speech processing in PWS $^{9}$ a reduction in the resting-state functional 
connectivity and cortical thickness in the left pars-opercularis, ${ }^{20}$ higher activity in the right inferior frontal gyrus ${ }^{21}$ and higher and more distributed neuronal activation in the right frontal operculum. ${ }^{22}$ But generally the conclusions which are drawn from fMRIs are to interpret with utmost caution. A single fMRI volume consists of 130,000 voxels (volumetric pixels) which implies that many steps of computation must be run through before the colored brain maps which so appeal to the emotions can be drawn. In this process there is a great risk that data will be corrupted, whether accidentally or half intentionally. Vuland Pashler ${ }^{23}$ showed that of 55 reports on social behavior using fMRI the correlations were not calculated acceptably: "Over half ... were reporting correlations measured on a region picked out precisely for having very high correlations". Experts reacted angrily when some young scientists ${ }^{24}$ presented a poster featuring "The Salmon of Doubt". In their experiment they positioned an Atlantic salmon in an fMRI-scanner, showed him a series of photos with social scenes and measured his brain reactions. In their analysis of the data they found several areas in the salmon's brain showing significant activity ( $p=$ $0.001)$... although the salmon had been dead all along. Why these false positive results? Every fMRI-session produces random noise and with the need to calculate many thousands of multiple correlations it is not easy to filter out these signals. Only the reliable correction of the random errors in multiple testing can avoid spurious positive results. Experts who felt criticized by the "Salmon of doubt" argued that they always correct the results obtained from multiple testing, but a retrospective analysis showed that in $25-40 \%$ of the studies no such corrections had been made. ${ }^{25}$ However the most substantial criticism leveled against fMRI studies is the fact that although the correlations between brain activities and experience or behavior are no more than descriptions of connections and no explanations of causes, many interpretations of fMRI results are presented as if they were proofs of a causality.

\section{The problem of the search for genetic causes}

Stuttering seems to be genetically linked. Pedigree studies and molecular-genetic analysis have yielded some very interesting results. The fact that stuttering is linked to mutations of the genes was initially detected on chromosome $12 .{ }^{8}$ Meanwhile over twenty loci of mutations which are associated with stuttering are known. It even has been possible to determine the age of one of these mutations: It is 572 generations or 14,300 years old. ${ }^{26}$ But what is the benefit of all this knowledge? Mutations cannot be inverted and the simple idea that the affected genes could be "turned off" is naive: genes control far-reaching basic metabolic functions. To block such genes would be fatal. ${ }^{27}$

Nevertheless, genetic and neurophysiological research has cemented the currently favored belief that fluency disorders have a physiological und genetic basis rather than a psychological one. Today stuttering is regarded a neuro developmental disorder, ${ }^{1}$ a movement disorder of speech linked to abnormal myelogenesis of speech-related fiber tracts, ${ }^{28}$ or a muscle spindle abnormity in one laryngeal muscle. ${ }^{29}$

\section{The problem of integration of hard and soft knowledge}

Knowledge about physiology and technology is called "hard knowledge" (because it can be expressed in exact measurable units) while knowledge about psychosocial relations is called "soft knowledge" (because experiences can only be expressed partially and imprecisely in measurable units). In medicine in general this struggle is described as the "medical model" vs. the "bio psychosocial model".
And the search for the causes of stuttering is still a fight between the two camps: There is "a pitiable lack of consensus among researchers, university teachers and practitioners... about the nature and cause of the disorder" ${ }^{30}$ The result of this inability to integrate the huge stores of knowledge about stuttering is reflected in such often repeated remarks as: "The exact cause of stuttering is still unknown", "The cause of stuttering is not known ..."28 and even "The true cause of stuttering remains unknown". ${ }^{8}$ Such statements are amazing in a double sense: On the one hand we have gained a lot of insights into the development of stuttering and on the other there is not a single phenomenon in the whole world which has only one precise cause, unless we are prepared to settle for simple answers. The assertion that the causes of stuttering are unknown presumably emerges from the fact that it releases the therapist or researcher from the need to take responsibility for the position they adopt in their professional behavior. If the causes of stuttering remain unknown, it is easy to wait and to continue to do what we have always done, without reflecting on which elements of the known background of the disease we personally favor ... and what scientific and personal reasons we may have for this.

In his "Psychology of Science" Abraham Maslow ${ }^{32}$ drew a distinction between fear-controlled (or deficit-motivated) and couragecontrolled (or growth-motivated) scientists. He showed that in our capacity as scientists and clinicians both these motivations are present in us. Our partly subconscious desire to control our environment in order to allay our fears makes us cool, sober, stern and suspicious and leads us to close the doors to real comprehension. The growthmotivated part of our interest, on the other hand, is not controlled by our fears and leaves us open to real creativity whose outcome may be surprising, sometimes even scary, but is often constructive and liberating as well.

But in the last 50years the representatives of mainstream stuttering research have continued to stress that psychology does not help in the understanding of fluency disorders. Bernstein Ratner ${ }^{27}$ says: "Experience ... does not appear to play a role in the etiology of the disorder", Manning and Beck ${ }^{33}$ characterize psycho-etiological thoughts as unnecessary stigmatization of individuals who stutter and Alpermann ${ }^{31}$ even declares that a purely psychological cause of stuttering can be excluded- as if anybody had ever claimed that psychological phenomena are the only ones that exist.

The psychosomatic roots attributed to stuttering in art, literature, and theater are - fortunately - ineradicable. There the disease is regarded as "a perpetuated trauma" which attempts to "exorcize the mental wounds with words". ${ }^{34}$ "The language in disequilibrium" 35 is shown in De Buysser's "Opérabègue" (Stuttering Opera) in which the disability is characterized as an act of resistance leading out of destructive human relationships to a new humanity. Tartiglia, the stuttering character in the Italian Commedia dell' Arte, is often clumsy but at the same time sensitive and farsighted. His disjointed way of speaking often results in ambiguities that disclose deeper realities.

And new scientific findings also show how rewarding the appreciation of the psychosocial approach to stuttering could be. For instance Ajdacic-Gross et al., ${ }^{36}$ report alarming risk factors on the basis of an analysis of 11,000 conscripts in the Swiss Armed Forces (408 of whom had stuttered in childhood): "mother or father with alcohol problems", "disabled mother", "anxiety disorders and obsessive compulsive disorder in family members and other relatives" and "parent from a foreign country". Koç37 proposes an approach "to cure stuttering through detecting, accepting, and dealing with thoughts and related feelings that cause stuttering”. If this approach 
became common reality, we would allow ourselves to ask deeper leading questions. When Nippold (the behavioristic Lidcombe-SLP cited in the Introduction) declares" "Ben's stuttering has increased in frequency and severity, resulting in numerous emotional outbursts at home", we would ask: Could he have other reasons for his emotional outbursts than stuttering? Perhaps not been listened to enough at home? Could these reasons be a cause of Ben's stuttering?

\section{The common therapeutic techniques for children who stutter (CWS)}

Until the end of the $19^{\text {th }}$ century the correction of speech disorders was consigned to schoolmasters. With the appearance of the profession of SLP in the early $20^{\text {th }}$ century specific forms of speech practice were introduced, some of which are still used today. In the following decades a large palette of therapeutic techniques emerged.

Modern therapies normally consist of combinations of fluency shaping and stuttering modification, perhaps supplemented with some sort of assertiveness-training and/or with accompanying counseling of the parents. The "most thoroughly evaluated and most highly published therapy approach for young children who stutter"27 is the Australian Lidcombe program. In this program the clinician teaches the parent how to monitor the severity of the child's stuttering each day. ${ }^{28}$ Initially the parent talks with the child about a book or a game for 15 minutes each day, ignoring any stuttering but commenting on fluent utterances. Later the parent moves to "online" therapy, reinforcing fluency and correcting stuttering (less frequently, but asking the child to repeat) during daily conversations. ${ }^{1}$ This strictly behaviorist approach, ${ }^{38}$ using techniques of reward and punishment treats the child as if it were the object of training, as "dogs and other animals" are trained, says Howell. ${ }^{39}$ Onslow and Packman ${ }^{30}$ are indignant at such an analogy, but they too cannot hide the fact that the Lidcombe program constantly communicates to the child in nonverbal ways the notion that the fluency of his utterances is more important than the content of his speech, than his imagination, needs and feelings.

\section{Reservation with systemic interventions}

Systemic Interventions which focus on the child-family interaction are not often used in the therapy of stuttering children. Such approaches as the concept of "The Safe Place" by Katz-Bernstein, the "Palin Parent-Child Interaction-Program" in London, ${ }^{40}$ the "familycentered program" developed at the Stuttering Center of Western Pennsylvania, ${ }^{41}$ a few approaches using "filial therapy", where parents are provided with basic play therapy skills to use at home ${ }^{42}$ and our own EFAS-project ("Evaluation of family dynamic aspects of Stuttering"), ${ }^{43}$ are the exceptions. Most SLPs do not use a standardized program to work with parents, although almost all emphasize that "collaboration with parents"12 is essential in working with stuttering children. Otherwise, the reality of counseling in clinical practice is often reduced to recording past medical history, a short information session after the therapy sessions and the elaboration of work to be done at home. ${ }^{44}$ It seems that many clinicians are uncomfortable working with parents at an effective level.

\section{The embarrassment of clinicians in counseling the parents}

The following reveals some of the dimensions of the embarrassment many clinicians feel in counseling the parents. i. SLPs and clinicians emphasize the importance of establishing a trusting, cooperative relationship with the parents: "A harmonic mutual trust between therapist and parents is basic". ${ }^{45}$ But such a relationship does not exist at the beginning of a counseling process. It has to be developed. This means for the clinician that before harmony with the parents can be achieved, he has not only to invite them to discuss matters frankly and to listen to them with empathy, but also to confront them with at times painful thoughts about possible relationships in the family dynamics.

ii. Normally the clinicians speak of counseling "the parents" but mostly they refer to the counseling of mothers and rarely to that of fathers. This discrepancy arises not only because some fathers have too tight a schedule but also because some mothers are afraid - if they come as couple - that familial dissonances could be unveiled and this can lead them prevail that their partner has no time for participation.

iii. The most difficult and often taboo issue in the counseling of parents is the matter of guilt, arising out of the question of whether the parents' behavior accounts for the development of the child's stutter. Many SLPs and clinicians unhelpfully advise the parents to "remove unmotivated feelings of guilt and blame". ${ }^{27}$ But feelings are never unmotivated and they cannot be commanded. They can be hidden, and this is exactly what happens when professionals advise the parents to forget their undesirable feelings.

iv. In parent counseling the point of view on the family is often narrowed down to the parent-child relationship. Grandparents are rarely mentioned although these are the most important persons when we try to understand - together with the parents - how the parents' own childhood has influenced their parenting style, with all its qualities and shortcomings.

This resistance to systemic, family-dynamic thinking and acting prevents a fruitful clinician-parent relationship and can lead the clinician either into a paralyzing state of reserve (unwillingness to annoy the parents) or alternatively into giving too much advice. Most clinicians have never learned to handle such situations, so EzratiVinacourand Weinstein ${ }^{12}$ are probably not the only ones who say: "As clinicians, we felt helpless, ambivalent, and embarrassed while interacting with parents of children who stuttered ..."

Without a dialog with parents in which he is guided by curiosity and courage, the clinician often stays in the bubble of the therapy room and fails to perceive the most important elements in the background of the stuttering children: the incriminatory fact of a serious illness of a parent or a sibling, the beneficial or destructive impact of a grandmother, the fact that the parents are separated or that serious financial problems have put family life under strain. Certainly for SLPs who are not psychotherapists it is difficult to consider these backgrounds in depth, but it is far better for each individual therapist to find the appropriate extent to which he can incorporate parts of them in therapeutic decision-making than to ignore them.

\section{A loophole out of the deadlock between hard and soft facts}

The resistance to systemic, family-dynamic action, and reservations or even fear about combining hard and soft knowledge mutually reinforce each other to create a near impenetrable obstacle which must be got rid of if further progress in the research and therapy of stuttering is to be pursued seriously. Just how imperative this is can be demonstrated by highlighting the amazing inconsistencies in defining the phenomenon "stuttering". Most experts agree with Sheehan's analogy of stuttering as an iceberg: Beneath the surface there exist a variety of negative psychological processes, including 
feelings of fear, shame, guilt, anxiety, hopelessness, isolation and denial. ${ }^{8}{ }^{19}$ Against this background it seems incredible that most modern standard definitions of stuttering address primarily the surface features of the dysfunction ${ }^{46}$ often expressed in the hard data of "stuttered syllables per minute". In other fields of comparable disorders experts have managed to bring different types of knowledge together more successfully. For instance, writer's cramp is understood as a focal dystonia and as a disturbance of psychogenic origin, so experts are free to assert that psychotherapeutic approaches will in certain cases be the most successful. Erythrophobia, the pathological form of the fear of blushing, is also a type of disorder with a severe and conspicuous organic appearance - as stuttering is. It is classified as a sub-syndrome of social phobia and is treated accordingly. Is stuttering something quite different from all other disabilities? How can we find a common and really shared view on the phenomenon?

One could suggest that if the search for causes comes up with such contradictory answers and if so many therapeutic approaches exist, perhaps it would make sense to skip the search for causes and instead ask which therapies are most successful. The answer should be found in the results of therapy outcome research.

\section{Outcome research in stuttering therapy}

Nye and Hahs-Vaughn ${ }^{47}$ reported in their assessment of the methodological quality of experimental and quasi-experimental trials in stuttering treatment research (analysis of 23 randomized RCTs out of 9 databases and 13 specialized journals) that the quality of external and internal validity was found to be substantively incomplete. Are RCTs, the gold-standard of research evidence, not suitable for issues which are only comprehensible when hard and soft facts are combined?

The term "evidence" in medicine appeared back in the $18^{\text {th }}$ century but it has had its modern meaning as in "Evidence Based Medicine" (EBM) since the 1990s, used for a special medical science based on empiric proofs."Evidence Based Practice“" (EBP),deduced from $\mathrm{EBM}$, is an interdisciplinary approach to clinical practice which integrates clinical expertise, best current evidence and client values. EBP has the same strength and weakness as EBM. Developed in the field of medicine for drug trials, EBM and EBP are helpful when it comes to improving safety in the design and use of new medicaments. But not everyone is convinced of its supposed applicability to almost every branch of medicine and to social science. In addition to the SLPs Mc Curtin and Roddam ${ }^{3}$ cited in the Introduction, many experts in other fields of research have expressed severe reservations with regards to the reliability and usefulness of EBP methodology. Critics concentrate mainly on the peer-review process of selecting the articles to be published (many biases) and the unsatisfactory use of Impact Factors (which favorite main stream knowledge). The most important allegation is that EBP focuses on strictly defined and narrowly restricted data which may result in a large loss of relevant information. In the case of speech language pathology this can easily be recognized in the meta-analysis of research into the behavioral treatment of stuttering by Herder, Howard, Nye and Vanryckeghem. ${ }^{48}$ In their search of the literature they identified 1798 articles on the topic, but when they examined them to see whether they complied with the inclusion criteria the number of articles was reduced step by $\operatorname{step}(1798>375>224>19>7)$ so that at last only 7 studies were included in the analysis. More than $99 \%$ of the collected information was ignored. Such harshness does not only devalue knowledge of subjective experience but also fosters the use of superficial definitions of stuttering: Stuttered syllables per minute is a countable unit. The surface behaviors of stuttering are an important part of the disorder but "they may not be the most critical factor to the person who stutters" ${ }^{46}$ Clinicians have known this for a long time. So it's not surprising that when SLPs are faced with clinical questions, the clinical experiences of colleagues dominate as the primary source of information for $99.6 \%$ of them. ${ }^{3}$ Individual experiences in personal contacts between scientists and clinicians and especially between clinicians and clients seem to have much more persuasive force than we dare to recognize. Many important variables in social research are not subject to randomization and experimental control, so that standard research paradigms should systematically include the use of rigorous qualitative methods. ${ }^{49} \mathrm{EBP}$ criteria are only appropriate under certain conditions. But what are the alternatives? Do other criteria for therapeutic outcome research exist? Perhaps psychotherapeutic outcome research can give an answer. In any case its promising to ask for the relevance of the results of psychotherapeutic outcome research for SLP and especially for stuttering therapy.

\section{The "Common Factors"}

More than 70years ago the American psychologist Saul Rosenzweig made a perplexing observation about the quest for the most effective psychotherapeutic technique: Different treatment procedures produce comparable results. He wrote: "There are inevitably certain un-recognized factors in any therapeutic situation - factors that may be even more important than those being purposely employed". ${ }^{50}$ Wampold et al., ${ }^{51}$ confirmed in a meta-analysis of 18 empirically validated therapy techniques that the differences between the different types of therapy as regards the extent of their effect were near zero. Wampold's ${ }^{52}$ estimation of the degree of different types of variance in psychotherapy outcome is:

I. Common factors that underlie all psychotherapies (> $70 \%)$,

II. Client differences (22\%) and

\section{Specific effects of a particular treatment $(<8 \%)$ (Table 1).}

In January 2011 a joint Task Force of the American Psychological Association completed a meta-analysis of the research on "Evidencebased Therapy Relationships". Its main conclusions are ${ }^{53-54}$

a.The therapy relationship acts in concert with treatment methods, patient characteristics and practitioner qualities in determining effectiveness.

b. The therapy relationship accounts for why clients improve (or fail to improve) at least as much as the particular treatment method.

c. Adapting or tailoring the therapy relationship to specific patient characteristics (in addition to diagnosis) enhances the effectiveness of treatment.

By far the largest proportion of the variation in psychotherapeutic outcome is ascribed to the "Common Factors": Clients respond more to the quality of the therapeutic relationship, rather than improve thanks to innovatory techniques and methods. The therapeutic relation and alliance develops largely beyond the realm of the verbal as Arizmendi ${ }^{55}$ explains in detail. Empathy, the key to the therapistpatient relationship has several preludes: physiological synchrony (in heart rate, skin conductance), emotional synchrony with mimicry (in facial expression, voice quality, postures and gestures) and imagery (a crucial element in the transition from simple attunement to empathy). Together they lead to emotional contagion, supported - as we have known for some years - by mirror neurons which activate the same area of the brain when we observe an action of another person as would be activated when we perform the action ourselves. 
Table I Therapeutic Outcome in Social Science

\begin{tabular}{lll}
\hline Therapeutic Outcome in Social Science & & \\
\hline Common factors (> 70\%) & Client differences (22\%) & Specific effects (<8\%) \\
\hline Therapeutic relationship & Patient characteristics & Particular Treatment \\
\hline Therapeutic alliance & Reactance level & Cognitive behaviour therapy \\
Empathy & Preferences of therapy methods & Rational-emotive therapy \\
Goal consensus & culture & Systemic therapy \\
Positive regard & Religion/spirituality & psychoanalysis \\
Congruence (genuineness) & Readiness for change & Fluency shaping \\
feedback & Coping style & Stuttering modification \\
Repair of alliance ruptures & Patient's expectations & Biofeedback(DAF/FAF) \\
Management of counter transference & Attachment style & Video-self-modeling \\
\hline Quality of relational interpretation & &
\end{tabular}

\section{Conclusion therapy \\ empathy-based}

Several SLPs have recognized that the significance of the "therapist factors" is underestimated. Perhaps the first was Albert Murphy, ${ }^{56}$ a psychologist who had been trained in stuttering therapy by the Iowa pioneers Lee Travis, Wendell Johnson and Charles van Riper, and who stayed in close contact with the pioneers of Humanistic Psychology, Kurt Goldstein, Carl Rogers, Gordon Allport and Abraham Maslow. Murphy wrote 37 years ago:

"We have long recognized that therapeutic success or failure is often attributable to the emotional relationship that exists between client and clinician, rather than to specific speech techniques. ... If there is one truth about stuttering therapy, I believe it is simply this: Our persons are more important than our techniques."

In an approach similar to Maslow's distinction between deficitmotivated and growth-motivated scientists Murphy distinguished between clinicians who have a need to control others and selfactualizing clinicians. The latter are more spontaneous and expressive, more natural, less self-controlled and inhibited, open to life in the larger sense, less upset by the unknown, the strange and the puzzling, and indeed may enjoy becoming absorbed in it. Murphy refers to his form of empathy-based treatment as "Person-oriented stuttering therapy" but points out that it can also be called "humanistic", "psychodynamic" or "personalistic".

Many of today's SLPs basically recognize the deep significance of the "therapist factors" in stuttering therapy. Yaruss and Bernstein Ratner $^{57}$ write: "The specific techniques used by clinicians are not necessarily as important as the broader understanding that clinicians can develop about stuttering - and about the specific individual or family with whom they are working at the time" and Millard and $\mathrm{Cook}^{58}$ declare that therapy itself is likely to be less important than the therapist and that a "therapeutic alliance" in an empathic and nonjudgmental view of the client's world is crucial. Bernstein Ratner ${ }^{27}$ calls for more attention to be paid to the therapists "ability to create an alliance" and Zebrowski and Arenas ${ }^{38}$ regret that Carl Rogers' exemplary demonstration of the therapeutic value of warmth, empathy and genuineness has not received enough attention in stuttering therapy research.

Acknowledgement of the importance of therapist factors in stuttering therapy can also be heard from people who stutter. Plexico, Manning and DiLollo ${ }^{59}$ asked 28 adult PWS for their view of what made an effective clinician. Some answers were:

"When a speech pathologist was interested in my whole life and how I was dealing with the world, what my dreams and wants from life were, then the speech therapy had a purpose."

"When I knew someone believed in me, I had more confidence to raise my hand in class or to read that speech or to speak to that room full of people. Whether or not I did it fluently didn't really matter."

"This SLP made me more comfortable by being interested in me as a person ... Her interest in me as an overall person made me feel better about myself as a stutterer, and that I was not just a person who needed to be 'fixed', that I was more."

\section{SLPs focusing on the "empathy-based treatment"}

Quesal $^{46}$ tags the intensified focusing of stuttering therapy on the therapist factors as "empathy-based treatment". This description indicates that in contrast to the medical model where stuttering is understood as an individual defect, in this approach stuttering is understood as a social phenomenon, and therefore a problem which can only be modified in deep and honest interactions with other individuals, preferably guided by a therapist who is interested in the whole iceberg of stuttering and not only in the tip that shows above the surface. In this form of therapy the goal is not necessarily to achieve fluency but - as King George demonstrated so clearly - "to find one's voice", ${ }^{8}$ to dare to show ones needs, feelings, thoughts, wishes and fears."Empathy" is the magic word to reach such a goal. It is the skill to recognize and understand the feelings, thoughts and motives of another human being. But there are different modes of empathy in which different mirror neuron systems are involved: ${ }^{60}$ Cognitive empathy is contingent on the fronto-cortical systems involved in the theory of mind and mentalizing and enables us to recognize what another person is thinking and feeling. Emotional empathy recruits areas that are typically involved in emotional processing (including facial expression and body posture) in the insula and thalamus and enable us to feel what another person is feeling. Empathy-based treatment has primarily to be based on emotional empathy, but this also implies dangers. It entails the risk of becoming emotionally affected and changed, and so even professionals can be trapped introducing their empathy to the cognition form.

Empathy-based Stuttering Therapy begins with a first careful request for the case history, which is then extended to a more detailed exploration in order to gain further clarification. ${ }^{58}$ It is crucial to get to understand the important points of the life situation of the family with a stuttering child. But it requires some courage. For instance to ask the parents how they and their child experience their contact with the grandparents could risk appearing too intrusive. But on the other hand it is extremely frustrating to discover by chance six months later that the parents of the child in therapy have been separated for 
several months or that one parent has been seriously ill for years. And empathy based diagnostic and therapy only functions if the child and his parents are aware of some basic attitudes adopted by the therapist:

\section{Basic attitudes adopted by the therapist}

For therapist of stuttering adults, stuttering children and their parents some attitudes are fundamental if they want to work in an empathic-based manner (Table 2a):

Respect for the symptom: The disfluency has its logical and psychological history and its perpetuation has a function in the homeostasis of the individual. It is not advisable, indeed, it is even disrespectful, to try only to get rid of the symptom. Clinicians need to show more interest in what the PWS says than in how he says it. ${ }^{59}$ They should help ensure that the emotional needs and injuries of the PWS become the focus of the interaction.

Table 2 Attitude and characteristics in empty-based stuttering therapy

\begin{tabular}{l}
\hline $\begin{array}{l}\text { Attitude and characteristics in empty- } \\
\text { based stuttering therapy }\end{array}$ \\
\hline I. Basic attitudes for therapists with PWS \\
\hline Respect for the symptom \\
\hline More interest in what the PWS says than in how he says it \\
\hline Comprehension of multiple generations \\
\hline Constructive understanding of feelings of guilt \\
\hline Elements of empathy-based therapy with children \\
\hline I.The children's part \\
\hline Elements of play therapy \\
\hline Encouraging to take the risk of Verbalizing their wishes and fears and \\
\hline To develop alternative to staying silent or exploding in emotional \\
outbursts \\
\hline Fluency play \\
\hline c) Counselling of parents \\
\hline Both parents invited \\
\hline Dialog with parents guided by curiosity and courage \\
\hline Considerations of connotations \\
\hline Detection of "affect display rules" \\
\hline Feelings of guilt taken seriously \\
\hline
\end{tabular}

Comprehension of multiple generations: It is especially beneficial if the parents of the CWS come to recognize the way in which they were brought up themselves, and how they thereby learned to be parents.

Constructive understanding of feelings of guilt: Feelings of guilt are emotional facts and never useless. It is helpful to learn to distinguish between different types of guilt. "Learned feelings of guilt" are unpleasant feelings which we have acquired because somebody (mostly a parent) has told us we "have to feel in such a way" in situations in which we had not in fact done anything wrong or deceitful but where the person making the demand found it easier to use this unfair instrument to control the child. If we identify feelings of guilt as having been learned, this enables us to dissociate ourselves from these feelings because we know that they no longer make sense (as adults we no longer have to please our parents). "Genuine feelings of guilt" are emotional reactions to real guilt. Guilt can be defined as the accompanying feeling when we have done something against the well-being of someone else or of ourselves. If we identify such feelings this gives us the triple chance to regret or grieve, to apologize and to take more care in the face of a similar situation in the future in which we could again do something that would make us feel guilty. (Table 2): Attitudes and characteristics in empathy-based stuttering therapy. Beside the basic attitudes adopted by the therapist some essential characteristics of empathy-based therapy for CWS and their parent scan be formulated:

\section{Elements of empathy-based therapy for stuttering children}

The child's part in empathy-based therapy (Table 2b) follows the instructions for nondirective play therapy developed by Virginia Axline ${ }^{61}$ founded on the work of Carl Rogers, ${ }^{62}$ a psychodynamic approach with excellent efficacy. ${ }^{63}$ The purpose of play therapy in SLP therapies is to help the children to express their emotions better through language. They are encouraged to take the risk of verbalizing their wishes, fears, and other feelings more often and to develop alternatives to staying silent or exploding in emotional outbursts. In this way they can discover for instance that being angry with their mother is not as dangerous as they imagined it to be. Elements of "stuttering modification" or "self-modeling" can be built in, but there is no place for "fluency shaping" - perhaps at most some "fluency play" chosen by the child.

\section{Elements of empathy-based counseling of the parents of CWS}

Many parents of CWS were raised in a home with authoritarian or indifferent/neglectful parents ${ }^{64,65}$ and therefore developed an increased emotional vulnerability with anxious mind-sets, unconscious longings, unacknowledged dislikes, and behavior stereotypes. For example, if in their own childhood family the parents experienced an atmosphere of suppressed dissatisfaction or, alternatively, a lot of open discord, they might have a tendency to avoid bringing conflicts out into the open in their own family and strive frantically for an appearance of harmony. Other parents who were brought up very strictly do not dare call this strictness into question and pass it on to their own child or, alternatively, do not have the confidence to set limits to their children. In yet other cases, one of their own parents had too strong an emotional attachment to them when they were children themselves and they are therefore in danger of taking over their own child or, alternatively, expecting it to become too independent too soon. Most parents with such personal histories have a strict idea of what their child ought to be like and their reactions range from disappointment to hurt if the child does not behave according to their expectations. The child is then caught up in a conflict of loyalties because it wants to remain true to itself, but on the other hand it attaches a lot of importance to the well-being of its parents. The functional speech disorder is one of many possible psychosomatic disorders unconsciously pushing to find a solution to such conflicts of loyalty, as described by the "unconscious need hypothesis". Certainly it is not appropriate to immediately ask the parents questions concerning these partly painful backgrounds. But other questions which lead in the same direction are possible early in the counseling of the parents: "What was your childhood like?", "What is your relationship to your parents today?" Often such simple questions lead to important insights e.g. to the fact that a very handson grandmother takes too much part in decision-making concerning the family of the CWS and the mother or the father has not had the confidence to set limits to her intervention for years.

Further pieces of advice can be beneficial in counseling parents of CWS (Table 2c).

Both parents: should be invited for counseling. If this is presented as a matter of course, not only one parent (usually the mother) but both will participate.

Consideration of connotations: Parents of CWS often unconsciously prefer a style of verbal communication which focuses on denotations (the dictionary meaning of words) because connotations (the 
emotional implications and associations that words may carry) can lead to inconvenient insights. ${ }^{13}$ Once parents realize that they are reacting mainly to the denotations of their child's utterances, they have the chance to stop and try to understand its connoted meaning instead.

Detection of "affect display rules": Parents' feelings of guilt should be taken very seriously. Most parents of CWS fear or feel that their parenting style could be one of the causal factors of their child's stuttering. It is possible to clarify how far they are right about this. Together with the clinician they can come to understand which guilt feelings are "learned" and which are "genuine", and the appropriate lesson can be drawn.

\section{Qualification of the new kind of clinician}

Traditionally the qualification of SLPs was defined by quantitative criteria: number of courses taken, completion of exams and degrees awarded. For SLPs working on the basis of empathy-based therapy other core areas of skills are required: a special ability to communicate, to recognize the client's needs and personal goals; to encourage participation and cognitive changes; to listen patiently and to build a trusting therapeutic alliance.$^{59}$ This last requirement is not to be confused with simply being polite. It means being willing to risk disputes, to reveal one's own thoughts at appropriate occasions and now and then show one's own feelings as well, despite the danger of creating a degree of open conflict with the CWS or his parents. Therapeutic alliance is an emerging quality of partnership and mutual collaboration between therapist and client built on a positive emotional bond (trust, respect, liking) and especially to respond non-defensively to a client's hostility or negativity. ${ }^{66}$ Empathy-based therapy cannot work with "technical dialogue" (where the purpose is frequently to persuade others to adopt a particular point of view), nor with "monologue disguised as dialogue" but only in "genuine dialogue", where clinicians and client are open to the otherness of their coparticipants. ${ }^{56}$ The therapist should allow himself to be vulnerable to accepting his own feelings, including his fears.

Working with PWS can be a deeply satisfying task but is now and then also an exhausting or even challenging adventure. The emotional reactions of SLPs towards the stuttering of PWS - their countertransference - are quite major. When graduate student clinicians in SLP were shown 30-second video clips of PWS and PWNS their emotional reactions towards the stuttering were striking: increase of skin conductance response, decrease of heart rate and a subjective increase of negative feelings. ${ }^{67}$ Not only this strain but also confusing forces arising from complex experiences in the therapist's own life story mean external supervision of the therapist's work is absolutely essential. Receiving expert supervision supports reflective practice in therapists and encourages them to be imaginative, experimental and innovative in the therapy they deliver. ${ }^{58}$

Empathy-based stuttering therapy might seem to be a very ambitious and challenging venture, and perhaps only suitable for some "chosen" clinicians. But this is a false perception, because it can be learned gradually in small steps starting with therapy beginners to therapy advanced learners, as Millard and Cook $^{58}$ explain sensitively (Table 3).

Such a learning process becomes successful when the therapist develops the openness to realize that not all of his academic knowledge serves in clinical practice, that he has learned too much of "looking at" instead of "looking along" as Rouse ${ }^{68}$ realized when he started clinical practice as an SLP:
"I believe I was trained well to identify the characteristics of various communication disorders as well as to evaluate and treat patients. I felt confident when I left my graduate program and entered the hospital environment that I knew what I was doing. But a big surprise quickly came. That surprise was the subjective experience patients and their families were relating to me. Fear, loss, frustration, loneliness, desperation, depression, acceptance, shock and anger these were experiences my patients were telling me, and I was frankly unprepared to deal with them. I had been trained to look at, after all, not look along."

Table 3 Progress from therapy beginners to advanced learners [40]

Progress from therapy beginners to advanced learners Millard and Cook (20I0)

\begin{tabular}{|c|c|}
\hline Therapy beginners show & $\begin{array}{l}\text { Therapy advanced learners } \\
\text { show }\end{array}$ \\
\hline $\begin{array}{l}\text { Negative automatic } \\
\text { thoughts }\end{array}$ & Constructive thoughts \\
\hline $\begin{array}{l}\text { "I will hear questions i can't } \\
\text { answer" }\end{array}$ & $\begin{array}{l}\text { "I have worked with PWS", "i know } \\
\text { about stuttering" }\end{array}$ \\
\hline "I won't be able to stop" & $\begin{array}{l}\text { "I can empathize","I have good } \\
\text { listening skills" }\end{array}$ \\
\hline "I won't look professional" & $\begin{array}{l}\text { "I don't have to have all the } \\
\text { answers" }\end{array}$ \\
\hline \multicolumn{2}{|l|}{ Affective response } \\
\hline Worried, anxious, nervous & Confident \\
\hline Lacking confidence & Calm \\
\hline \multicolumn{2}{|l|}{ Physical responses } \\
\hline Butterflies in tummy & Relaxed \\
\hline Sweaty palms, blushing & Steady heart rate \\
\hline \multicolumn{2}{|l|}{ Heart racing, tense } \\
\hline \multicolumn{2}{|l|}{ Behavioural responses } \\
\hline Consider ways to avoid situation & Maintain eye contact \\
\hline Avoid eye contact, talk quickly & Allow pauses in conversation \\
\hline Find it hard to concentrate/listen & Be able to concentrate and focus \\
\hline Become more directive, fidgeting & Respond to needs of family \\
\hline
\end{tabular}

\section{Acknowledgments}

None.

\section{Conflicts of interest}

Author declares there are no conflicts of interest.

\section{Funding}

None.

\section{References}

1. Nippold MA. Stuttering in school-age children: a call for treatment research. Lang Speech Hear Serv Sch. 2011;42(2):99-101.

2. Yaruss JS, Coleman CE, Quesal RW. Stuttering in school-age children: a comprehensive approach to treatment. Lang Speech Hear Serv Sch. 2012;43(4):536-548.

3. McCurtin A, Roddam H. Evidence-based practice: SLTs under siege or opportunity for growth? The use and nature of research evidence in the profession. Int J Lang Commun Disord. 2012;47(1):11-26.

4. Erickson S, Perry A. Letter to the editor. Regarding 'McCurtin A and Roddam H 2012 Evidence-based practice: SLTs under siege or opportunity for growth? The use and nature of research evidence in the profession. Int J Lang Commun Disord. 2012;47(1):11-26. 
5. Nippold MA. Comment / Reply: When a school-age child stutters, let's focus on the primary problem. Lang Speech Hear Serv Sch. 2012;43(4):549-551.

6. Pring T. Ask a silly question: two decades of troublesome trials. Int $J$ Lang Commun Disord. 2004;39(3):285-302.

7. Au-Yeung J, Cook F. Clinical evolution: moving forward by looking back. J Fluency Disord. 2011;36(3):141-143.

8. Ghiselli N, Davis G. Stuttering: Fact or fiction? PsycCRITIQUES . 2011;56(13).

9. Chang SE. Using brain imaging to unravel the mysteries of stuttering. Cerebrum. 2011;12.

10. Palmer J. The King's Speech: A Jungian take. Jung Journal: Culture \& Psyche. 2012;6(2):68-85.

11. Frankel B. The King's Speech and The Fighter: A review of two Academy Award selections. Group. 2011;35(4):353-355.

12. Ezrati-Vinacour R, Weinstein N. A dialogue among various cultures and its manifestation in stuttering therapy. $J$ Fluency Disord. 2011;36(3):174-185.

13. Kollbrunner J. Psychodynamik des Stotterns. Psychosoziale Ursachen, Stottertheorien, tiefenpsychologisch orientierte Therapie, Zukunftsperspektiven der Sprachtherapieausbildung. Kohlhammer, Germany. 2004. p.456.

14. Murphy AT, Fitz-Simons RM. Stuttering and personality dynamics: play therapy, projective therapy, and counseling. Ronald Press Company, New York, USA. 1960. p.519.

15. Sheehan JG. Stuttering: Research and therapy. Harper \& Row, New York, USA. 1970

16. Krause MP. Stottern als Beziehungsstörung. Psychotherapeutische Arbeit mit Eltern stotternder Kinder. Praxis der Kinderpsychologie und Kinderpsychiatrie. 1985;34 (1):15-18.

17. Krause R. Sprache und Affekt. Das Stottern und seine Behandlung. Stuttgart: Kohlhammer. 1981.

18. Mrochen S. Gedanken zur systemischen Verarbeitung von Stottern. In: J. A. Renner (Ed.): Stottern und Familie. 5. Stotterkonferenz der ivs (p. 124-132). Darmstadt: IVS. 2000.

19. Blomgren M. Stuttering treatment for adults: An update on contemporary approaches. Semin Speech Lang . 2010;31(4):272-282.

20. Lu C, Chen C, Peng D, et al. Neural anomaly and reorganization in speakers who stutter: A short-term intervention study. Neurology. 2012;79(7):625-632.

21. Loucks T, Kraft SJ, Choo AL, et al. Functional brain activation differences in stuttering identified with a rapid fMRI sequence. J Fluency Disord. 2011;36(4):302-307.

22. Neumann K, Euler HA, von Gudenberg AW, et al. The nature and treatment of stuttering as revealed by fMRI. A within- and betweengroup comparison. J Fluency Disord. 2003;28(4):381-409.

23. Vul E, Pashler H. Voodoo and circularity errors. NeuroImage. 2012;62(2):945-948.

24. Bennett C, Baird M, Miller AA, et 1. Neural correlates of interspecies perspective taking in the post-mortem Atlantic Salmon: An argument for multiple comparisons correction. 2009.

25. Bennett CM, Baird AA, Miller MB, et al. Neural correlates of interspecies perspective taking in the post-mortem Atlantic Salmon: An argument for proper multiple comparisons correction. Journal of Serendipitous and Unexpected Results. 2010;1(1):1-5.

26. Fedyna A, Drayna D, Kang C. Characterization of a mutation commonly associated with persistent stuttering: evidence for a founder mutation. $J$ Hum Genet. 2011;56(1):80-82.
27. Bernstein Ratner N. Translating recent research into meaningful clinical practice. Semin Speech Lang. 2010;31(4):236-249.

28. O'Brian S, Onslow M. Clinical management of stuttering in children and adults. BMJ . 2011;342:d3742.

29. Schuster SH, Schuster FMA. Muscle spindle abnormity in one laryngeal muscle would be sufficient to cause stuttering. Med Hypotheses. 2012;79(1):34-37.

30. Onslow M, Packman A. Stuttering studies support treatment. Nature. 2011;470(7335):465.

31. Alpermann A. Redeflusstorung: Stottern - einepsychischeStörung? SpracheStimmeGehör. 2010;34(2):56.

32. Maslow AH.The Psychology of Science. Harper \& Row, New York, USA. 1996.

33. Manning WH, Beck JG. Comments concerning Iverach, et al., Screening for personality disorders among adults seeking speech treatment for stuttering. J Fluency Disord. 2011;34(3):173-186.

34. Mueller P. The impediment that cannot say its name": Stammering and trauma in selected American and British texts. Anglia - Journal of English Philology. 2012;130(1):54-74.

35. Stalpaert C. The creative power in the failure of word and language. On silence, stuttering and other performative intensities. Arcadia International Journal for literary studies. 2010;45(1):77-93.

36. Ajdacic-Gross V, Vetter S, Muller M, et al. Risk factors for stuttering: a secondary analysis of a large data base. Eur Arch Psychiatry Clin Neurosci. 2010;260(4):279-286.

37. Koc M. The effect of cognitive-behavioral therapy on stuttering. Social Behavior and Personality. 2010;38(3):301-310.

38. Zebrowski PM, Arenas RM. The "Iowa Way" revisited. J Fluency Disord. 2011; 36(3):144-157

39. Howell P. Listen to the lessons of The King's Speech. Nature. 2011;470(7332):7.

40. Millard SK, Nicholas A, Cook FM. Is parent-child interaction therapy effective in reducing stuttering? J Speech Lang Hear Res. 2008;51(3):636-650.

41. Yaruss JS, Coleman C, Hammer D. Treating preschool children who stutter: description and preliminary evaluation of a family-focused treatment approach. Lang Speech Hear Serv Sch. 2006;37(2):118-136.

42. Andronico MP, Blake I. The application of filial therapy to young children with stuttering problems. J Speech Hear Disord. 1971;36(3):377-381.

43. Kollbrunner J, Fritschi S, Zimmermann A, et al. Stottern als familiäre Kommunikationsstörung. 2010.

44. Dehnhardt C, Ritterfeld U. Modelle der Elternarbeit in der sprachtherapeutischen Intervention. Sprachheilarbeit. 1998;43:128-136.

45. Unger JP, Berg M. Elternberatung in der Therapie des frühkindlichen Stotterns. SpracheStimme Gehör. 2013;37(1):19-23.

46. Quesal RW. Empathy: perhaps the most important E in EBP. Semin Speech Lang. 2010;31(4):217-226.

47. Nye C, Hahs-Vaughn D. Assessing methodological quality of randomized and quasi-experimental trials: a summary of stuttering treatment research. Int J Speech Lang Pathol. 2011;13(1):49-60.

48. Herder C, Howard C, Nye C, et al. Effectiveness of Behavioral Stuttering Treatment: A Systematic Review and Meta-Analysis. Contemporary Issues in Communication Science and disorders. 2006;33:61-73.

49. Norcross JC, Hill CE. Empirically supported therapy relationships. The Clinical Psychologist .2 004;57(3):19-24. 
50. Rosenzweig S. Some implicit common factors in diverse methods of psychotherapy. American Journal of Orthopsychiatry. $1936 ; 6(3): 412-415$

51. Wampold BE, Mondin GW, Moody M, et al. A Meta-Analysis of Outcome Studies Comparing Bona Fide Psychotherapies: Empirically, “All Must Have Prizes”. Psychological Bulletin. 1997;122(3):203-215.

52. Wampold BE. Great Psychotherapy Debate: Models, Methods, and Findings. Lawrence Erlbaum Publishers, USA. 2001. p.263.

53. Norcross JC, Wampold BE. Evidence-based therapy relationships: Research Conclusions and clinical practices. Psychotherapy (Chic) . 2011;48(1):98-102.

54. Norcross J C, Wampold B E. What works for whom: Tailoring psychotherapy to the person. J Clin Psychol. 2011;67(2):127-132.

55. Arizmendi T. Linking mechanisms: Emotional Contagion, Empathy, and Imagery. Psychoanalytic Psychology. 2011;28(3):405-419.

56. Murphy AT . Authenticity and creativity in stuttering theory and therapy. J Commun Disord. 1977;10(1-2):25-36.

57. Yaruss JS, Bernstein Ratner N. Becoming an effective clinician for people who stutter: you can do it! Semin Speech Lang. 2010;31(4):283-285.

58. Millard SK, Cook FM. Working with young children who stutter: raising our game. Semin Speech Lang. 2010;31(4):250-261.

59. Plexico LW, Manning WH, DiLollo A. Client perceptions of effective and ineffective therapeutic alliances during treatment for stuttering. $J$ Fluency Disord. 2010;35(4):333-354.
60. Nummenmaa L, Hirvonen J, Parkkola R, et al. Is emotional contagion special? An fMRI study on neural systems for affective and cognitive empathy. Neuroimage. 2008; 43(3):571-580.

61. Virginia Axline M. Play therapy. Ballantine Books, New York, USA. 1981.

62. Rogers C R.Client centered therapy. Constable. 1951.

63. Bratton SC, Ray D, Rhine T. The efficacy of play therapy with children: A meta-analytic review of treatment outcomes. Professional Psychology: Research and Practice. 2005;36(4):376-390.

64. Glauber IP. Stuttering. A psychoanalytic understanding. Human Sciences Press, New York, USA. 1982. p.170-176.

65. Barbara DA. The psychodynamics of stuttering. In: D. A. Barbara (Ed.): Psychological and psychiatric aspects of speech and hearing. Springfield. 1960. p. 363-384.

66. Horvath AO, Del Re AC, Flückiger $\mathrm{Ch}$, et al. Alliance in individual psychotherapy. In: Norcross John C (Ed.), Evidence-based therapy relationships. 2010.

67. Guntupalli VK, Nanjundeswaran C, Dayalu VN, et al. Autonomic and emotional responses of graduate student clinicians in speechlanguage pathology to stuttered speech. Int J Lang Commun Disord. 2012;47(5):603-608.

68. Rouse MH. Perspectives: Looking as and along communication disorders. The ASHA Leader. 2012. 